\title{
Pemantauan Keanekaragaman Hama dan Musuh Alami Tanaman Ubi Jalar dengan Pitfall Trap
}

\author{
Monitoring the Diversity of Pests and Natural Enemies of Sweet Potato Plants \\ with Pitfall Trap
}

Eko Apriliyanto ${ }^{1}$, Arum Asriyanti Suhastyo ${ }^{2}$

${ }^{1,2}$ Program Studi Agroindustri, Politeknik Banjarnegara Jawa Tengah

\begin{tabular}{l} 
ARTICLE INFO \\
\hline Article history: \\
DOI: \\
10.30595/pspfs.v2i.173 \\
Submitted: \\
July 29, 2021 \\
Accepted: \\
Sept 10, 2021 \\
Published: \\
Nov 10, 2021 \\
\hline
\end{tabular}

Keywords:

Diversity, Monitoring, Natural Enemies, Pests, Pitfall

\begin{abstract}
The abundance of pest and natural enemy populations on a land can be given in the diversity and abundance of feeding sources and other available resources. The purpose of this study was to determine the diversity of pests and natural enemies of sweet potato plants. Research on land with three types of sweet potatoes, namely yellow sweet potatoes with narrow leaves, yellow sweet potatoes with broad leaves, and sweet potatoes with white leaves. Around the research area are long beans, papaya, guava, soursop, and durian. Sampling of pests and natural enemies by using a pitfall trap. The data analyzed was in the form of the Shannon-Weaver $\left(\mathrm{H}^{\prime}\right)$ diversity index. The index of pest diversity of the order Coleoptera on narrow-leaved yellow sweet potato, broad-leaved yellow sweet potato, and white sweet potato was 0,$160 ; 0,1270$; and 0,1300 . The index of pest diversity of the order Orthoptera on narrow-leaved yellow sweet potato, broad-leaved yellow sweet potato, and white sweet potato was 0,$3585 ; 0,3599$; and 0,3632 . The index of pest diversity of the order Hemiptera on narrowleaved yellow sweet potato, broad-leaved yellow sweet potato, and white sweet potato was 0,$0635 ; 0,0771$; and 0,1300 . Diversity index of natural enemies of the order Araneae on narrow-leaved yellow sweet potato, broad-leaved yellow sweet potato, and white sweet potato $0.2180 ; 0.3061$; and 0.2705 . The three sweet potato fields had a low diversity index.
\end{abstract}

This work is licensed under a Creative Commons Attribution 4.0 International License.

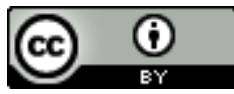

\section{Corresponding Author:}

Eko Apriliyanto

Program Studi Agroindustri

Politeknik Banjarnegara Jawa Tengah Indonesia

Email: okeapriliyanto@gmail.com

\section{PENDAHULUAN}

Ubi jalar (Ipomoea batatas) merupakan salah satu komoditi tanaman pangan yang pemanfaatan hasilnya berupa umbi. Hasil umbi yang berkualitas dapat diketahui melalui kulit umbi yang bersih tanpa cacat, bagian dalam umbi juga tidak rusak dan tidak berlubang. Penampilan umbi akan menentukan kualitas umbi untuk meningkatkan kesukaan konsumen. Konsumen akan lebih memilih umbi yang penampilannya baik dan tidak terdapat kerusakan fisik pada ubi jalar. Bentuk fisik ubi jalar yang baik dapat diperoleh melalui kegiatan budidaya yang baik. Budidaya tanaman ubi jalar dengan menghindari adanya kerusakan fisik pada hasil umbi yang dipanen. Kerusakan fisik umbi dapat disebabkan oleh alat pertanian dan adanya serangan organisme pengganggu tanaman (OPT). Saleh et al., (2015) kerusakan tanaman ubi jalar dari serangan hama dapat dipengaruhi oleh jenis hama yang menyerang, tingkat ketahanan tanaman terhadap hama, umur tanaman, dan periode lamanya serangan hama. Tanaman yang 
terlambat ditanam, memiliki peluang terjadinya serangan lebih lama oleh karena itu kehilangan hasil yang ditimbulkan akan semakin tinggi. Selain dapat mengurangi hasil umbi, serangan hama juga mengakibatkan penurunan kualitas agronomi lainnya (bahan tanam stek).

Jenis organisme pengganggu tanaman (OPT) yang menyebabkan kerugian langsung pada ubi jalar yaitu OPT yang menyerang umbi. Upaya pencegahan serangan OPT pada bagian umbi dapat dilakukan sejak tanaman ubi jalar belum menghasilkan umbi. Saat tanaman masih di awal tanam hingga mulai terbentuk umbi juga perlu dilakukan pencegahan kerusakan oleh OPT. Kerusakan tidak langsung pada ubi jalar yaitu adanya serangan OPT yang menyerang daun, batang, akar, dan bagian tanaman lainnya. Upaya peningkatan hasil umbi dapat dilakukan dengan mengurangi kerusakan bagian lain selain umbi. Daun berperan penting dalam kegiatan fotosintesis, sehingga perlu menjaga agar daun juga tidak terserang OPT. Bagian tanaman lainnya juga dihindarkan adanya serangan OPT.

Penelitian sebelumnya di wilayah Kota Tomohon dan Kabupaten Minahasa (Kecamatan Kawangkoan dan Kakas) tentang hama penting yang teridentifikasi berdasarkan karakter morfologi, sifat serangan, dan kerusakannya terdapat beberapa ordo penting yaitu Orthoptera, Coleoptera, Lepidoptera, dan Hemiptera. Beberapa ordo tersebut menyerang tanaman ubi jalar sejak berumur satu bulan sampai lebih empat bulan sesudah tanam. Jenis hama penting pada umur tanaman 1 bulan setelah tanam terdapat 3 yaitu kepik Coreidae perusak daun, Cicadelidae perusak daun, ordo Lepidoptera berupa larva perusak daun Spodoptera sp. (Noctuidae) (Pinontoan et al., 2011). Hama lain yang menyerang tanaman antara lain ulat jengkal (Geometridae sp.), ulat bulu (Macrothylacia rubi), belalang (Valanga sp.), penggerek batang (Omphisia anastomasalis), kepik (Physomerus grossipes) dan kumbang boleng (Cylas formicarius). Jenis hama penggerek batang juga menimbulkan kerusakan tanaman yang cukup parah, berupa patah cabang akibat gerekan pada bagian dalam batang (Setiawan et al., 2019).

Pitfall trap (perangkap jebakan) dapat digunakan untuk menangkap serangga yang hidup di atas permukaan tanah. Pada masing-masing titik pengambilan contoh dapat ditanam gelasplastik air mineral, gelas tersebut diisi larutan deterjen untuk membuat mecegah serangga pergi atau keluar dari permukaan air tersebut. Tanah yang sudah digali dimasukkan pitfall trap dan dibuat rata dengan permukaan tanah, sehingga serangga mudah terjebak pada saat melewati perangkap tersebut (Warohmah et al., 2018). Kelimpahan populasi serangga pada suatu habitat ditentukan oleh adanya keanekaragaman dan kelimpahan sumber makanan maupun sumber daya lain yang tersedia pada habitat tersebut. Keadaan sumber makanan yang berfluktuasi secara musiman akan menjadi faktor pembatas untuk keberadaan populasi organsme di suatu habitat oleh adanya kompetisi antar individu (Pinontoan et al., 2011).

Upaya pengendalian OPT dapat dilakukan dengan tepat apabila dilakukan tepat sasaran. Sasaran OPT sebagai target upaya pengendalian perlu dilakukan identifikasi dahulu agar penangannya juga lebih tepat. Identifikasi dapat dilakukan pada gejala tanaman sakit dan jenis OPT penyebabnya. Upaya ini dapat dilakukan dengan kegiatan pemantauan terhadap lahan tanaman budidaya. Pemantauan lahan ubi jalar dapat dilakukan menggunakan pada organisme yang berasosiasi dengan tanaman ubi jalar. Organisme yang perlu pemantuan intensif yaitu hama dan musuh alaminya. Keberadaan hama dan musuh alami pada tanaman ubi jalar dapat digunakan untuk pengambilan keputusan terhadap upaya pengendalian yang tepat. Oleh karena itu, perlu dikaji tentang pemantauan keanekaragaman hama dan musuh alami tanaman ubi jalar dengan pitfall trap. Tujuan dari penelitian ini yaitu mengetahui keanekaragaman hama dan musuh alami tanaman ubi jalar.

\section{METODE PENELITIAN}

\section{Peyiapan Tanaman Ubi Jalar}

Waktu penelitian pada bulan Mei 2021 di lahan Politeknik Banjarnegara yang berlokasi di Kelurahan Kenteng, Kecamatan Madukara, Kabupaten Banjarnegara, Jawa Tengah, 323 m dpl (BPS Kabupaten Banjarnegara, 2014). Lahan tanaman ubi jalar dengan cara tanam konvensional petani. Lahan dengan ukuran $11 \mathrm{~m} \mathrm{x} 14 \mathrm{~m}$ di buat bedengan ukuran $1 \mathrm{~m}$ x $11 \mathrm{~m}$ dengan pemberian pupuk dasar 1 karung $( \pm 30 \mathrm{~kg})$ pupuk kotoran kambing saat pengolahan lahan yang disebar pada tiap bedengan. Tanaman ubi jalar yang digunakan saat pengamatan berumur 2 bulan.

\section{Penggunaan Pitfall Trap}

Penelitian pada lahan dengan tiga jenis ubi jalar yaitu $\mathrm{A}=$ ubi jalar kuning berdaun sempit, $\mathrm{B}=\mathrm{ubi}$ kuning berdaun lebar, dan $\mathrm{C}=$ ubi jalar putih. Sekitar lahan penelitian berupa tanaman kacang panjang, pepaya, jambu biji, sirsak, dan durian. Pengambilan contoh hama dan musuh alami dengan menggunakan pitfall trap (perangkap jebak). Guru et al., (2016), pitfall trap digunakan untuk menjebak serangga dan artropoda lain pada permukaan tanah. Penggunaan pitfall trap di lahan ubi jalar sebagai berikut:

1. Pitfall trap berupa gelas plastik air mineral ukuran $220 \mathrm{~mL}$ yang ditanam dalam tanah dengan posisi mulut gelas sejajar dengan permukaan tanah. 
2. Gelas air mineral diisi dengan larutan deterjen dengan konsentrasi $23 \mathrm{~g}$ deterjen ditambah $25 \mathrm{~L}$ air (Siregar et al., 2014) dan dibiarkan selama 24 jam.

3. Pemasangan pitfall trap pada pagi hari pukul $10.00 \mathrm{WIB}$.

4. Pitfall trap diletakkan pada masing-masing perlakuan (ketiga jenis lahan ubi jalar) secara sistematis membentuk huruf $\mathrm{Z}$ pada 7 titik, sehingga terdapat 21 unit penelitian.

5. Seluruh spesimen hama dan musuh alami yang diperoleh selanjutnya dilakukan identifikasi pada tingkat ordo dan dilakukan penghitungan populasinya.

\section{Analisis Data}

Data dianalisis menurut Odum \& Barrett (2005), berupa indeks keanekaragaman Shannon-Weaver (H') dan kelimpahan relatif (KR). Indeks keanekaragaman (H') hama dan musuh alami menggunakan rumus sebagai berikut:

$$
\begin{aligned}
& \mathrm{H}^{\prime}=-\sum_{\mathrm{i}=1}^{\mathrm{n}} \text { pi ln pi } \\
& \mathrm{pi}=\frac{\mathrm{ni}}{\mathrm{N}}
\end{aligned}
$$

\section{Keterangan :}

$\mathrm{H}^{\prime}=$ Indeks Keragaman Shannon-Weaver

pi $=$ Proporsi jumlah individu ke-1 dengan jumlah total individu

ni $=$ Spesies ke-i

$\mathrm{N}=$ Jumlah total individu

Tolak ukur indeks keanekaragaman dapat dilihat pada Tabel 1. (Restu, 2002).

Tabel 1. Nilai Tolak Ukur Indeks Keanekaragaman

\begin{tabular}{ll}
\hline \multicolumn{1}{c}{ Nilai tolak ukur } & \multicolumn{1}{c}{ Keterangan } \\
\hline $\mathrm{H}^{\prime}<1,0$ & $\begin{array}{l}\text { Keanekaragaman rendah, miskin, produktivitas sangat rendah sebagai } \\
\text { indikasi adanya tekanan yang berat dan ekosistem tidak stabil }\end{array}$ \\
$1,0<\mathrm{H}^{\prime}<3,322$ & $\begin{array}{l}\text { Keanekaragaman sedang, produktivitas cukup, kondisi ekosistem cukup } \\
\text { seimbang, tekanan ekologis sedang. }\end{array}$ \\
& $\begin{array}{l}\text { Keanekaragaman tinggi, stabilitas ekosistem mantap, produktivitas tinggi, } \\
\text { tahan terhadap tekanan ekologis. }\end{array}$ \\
\hline
\end{tabular}

Rumus kelimpahan relatif (KR) hama dan musuh alami dengan rumus sebagai berikut:

$$
\mathrm{KR}=\frac{\mathrm{ni}}{\mathrm{N}} \times 100 \%
$$

Keterangan:

$\begin{array}{lll}\mathrm{KR} & =\text { Kelimpahan relatif }(\%) \\ \mathrm{ni} & =\text { Jumlah individu dan spesies ke-i } \\ \mathrm{N} & =\text { Jumlah total individu }\end{array}$

Struktur komunitas hama dan musuh alami dengan menghitung nilai indeks kemerataan antar jenis atau indeks Evennes (E) menurut (Magurran, 2004) sebagai berikut :

$$
E=\frac{H^{\prime}}{\ln (S)}
$$

Keterangan :

$$
\begin{array}{lll}
\mathrm{E} & = & \text { Indeks kemerataan jenis } \\
\mathrm{H} & = & \text { Indeks Shannon } \\
\mathrm{ln} & = & \text { Logaritma natural } \\
\mathrm{S} & = & \text { Jumlah jenis yang ditemukan }
\end{array}
$$

\section{HASIL DAN PEMBAHASAN}

Hasil pengamatan menggunakan pitfall trap menunjukkan bahwa hama yang berasosiasi dengan tanaman ubi jalar berupa jangkrik, larva kumbang, kumbang dewasa, wereng, dan kepik. Musuh alami yang diperoleh 
berupa predator yaitu laba-laba, sedangkan jenis serangga lainnya yaitu semut, tawon, dan nyamuk. Kelompok hama berdasarkan ordo serangga yang diperoleh pada pitfall trap yaitu Orthoptera, Coleoptera, dan Hemiptera. Kelompok musuh alami yang diperoleh yaitu ordo Araneae, sedangkan jenis serangga lainnya yaitu ordo Hymenoptera dan Diptera.

Hasil pemantauan hama dan musuh alami pada tanaman ubi jalar kuning berdaun sempit (Gambar 1.) menunjukkan bahwa sebagian besar organisme yang terperangkap pada pitfall trap berupa jenis serangga lainnya yang berperan netral dari ordo Hymenoptera berupa semut dan tawon, serta ordo Diptera berupa nyamuk dengan jumlah persentase seluruhnya yaitu 58\%. Pada urutan berikutnya populasi hama sebanyak $33 \%$ dan musuh alami sebanyak 9\%. Putri et al., (2017), menjelaskan bahwa makrofauna tanah memiliki peranan besar pada proses dekomposisi, aliran karbon, redistribusi unsur hara, siklus unsur hara, dan pembentukan struktur tanah. Faktor lingkungan juga dapat mempengaruhi aktivitas organisme tanah seperti iklim (curah hujan, suhu), tanah (kemasaman, kelembaban, suhu tanah, hara), vegetasi, dan cahaya matahari.

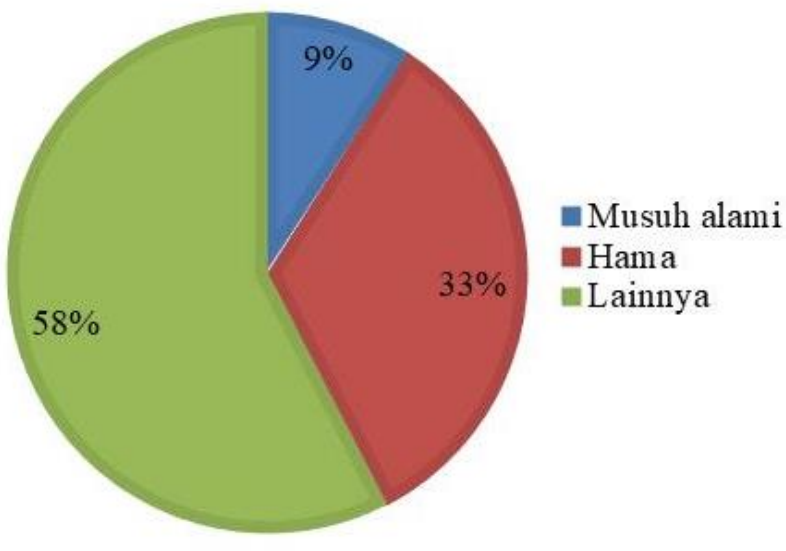

Gambar 1. Persentase hama dan musuh alami tanaman ubi jalar kuning berdaun sempit $(\mathrm{n}=66)$

Pemantauan pada lahan ubi jalar kuning berdaun lebar (Gambar 2.) menunjukkan populasi terbesar yaitu jenis serangga lainnya sebanyak $47 \%$ yang berperan sebagai serangga netral, diikuti serangga hama dengan sebanyak $35 \%$, dan musuh alami sebanyak $18 \%$. Jenis serangga lainnya ini berupa serangga netral berupa semut (Hymenoptera). Basna et al., (2017) Hymenoptera merupakan ordo yang dominan ditemukan selama penelitiannya di lahan perkebunan maupun hutan. Beberapa penelitian juga melaporkan bahwa ordo Hymenoptera merupakan jenis serangga tanah yang banyak diperoleh. Persentase ordo Hymenoptera dibandingkan dengan serangga tanah lainnya dapat melebihi 50\%. Penelitian Afriani \& Suati, (2021) juga menyatakan bahwa tingginya populasi ordo Hymenoptera berupa semut dikarenakan kondisi ini mendukung keberadaan organisme pengurai tanah yang merupakan makanan bagi serangga predator.

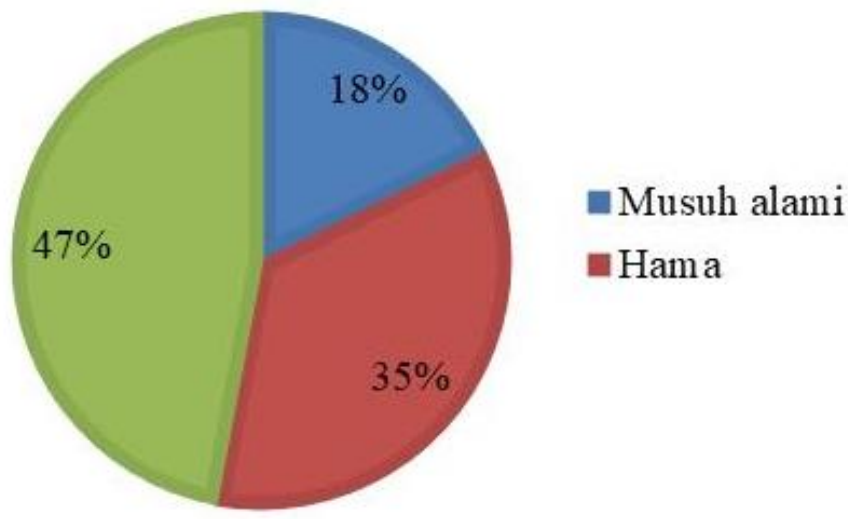

Gambar 2. Persentase hama dan musuh alami tanaman ubi jalar kuning berdaun lebar $(\mathrm{n}=51)$.

Pemantauan pada lahan ubi jalar putih (Gambar 3.) menunjukkan bahwa populasi tertinggi pada jenis serangga lainnya yang berperan netral yaitu $47 \%$, diikuti populasi serangga hama yaitu 39\%, dan musuh alami sebanyak 14\%. Jenis serangga didominasi oleh semut. Oktafitria et al., (2019) spesies semut memiliki sifat dapat bergerak aktif diatas permukaan tanah pada serasah daun di bawah pepohonan maupun pada lubanglubang di tanah yang menjadi sarangnya. 


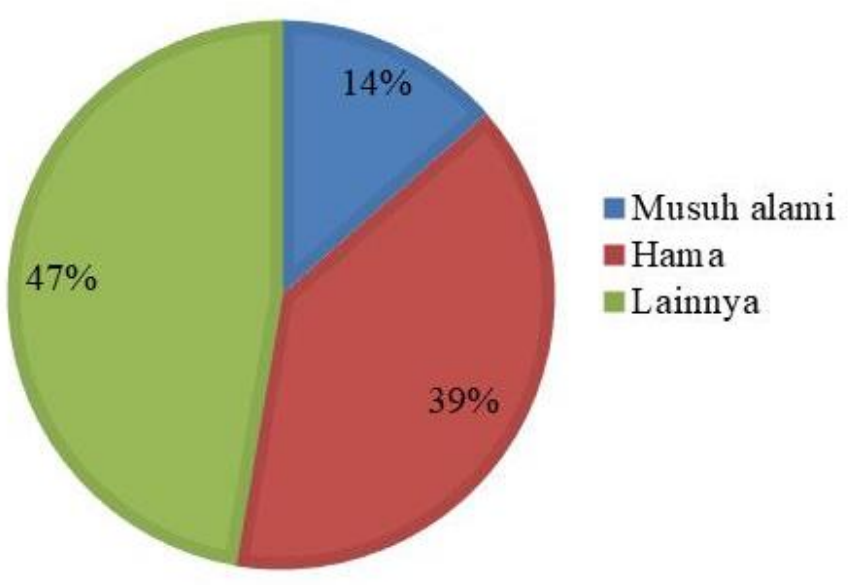

Gambar 3. Persentase hama dan musuh alami tanaman ubi jalar putih $(n=74)$.

Peran serangga dan artropoda yang berasosiasi dengan tanaman ubi jalar berupa hama, musuh alami, dan serangga netral. Berdasarkan Tabel 2. menunjukkan bahwa nilai H' pada ketiga lahan ubi jalar dengan tingkat keanekaragaman rendah. Tingkat keanekaragaman hama, musuh alami, dan serangga netral seluruhnya dengan nilai $H^{\prime}<1,0$. Nilai $H^{\prime}<1,0$ berarti ketiga lahan ubi jalar memiliki kategori keanekaragaman rendah, hal ini menunjukkan lahan tersebut memiliki jumlah jenis dan individu kurang beragam dan ekosistemnya tidak stabil. Musuh alami yang diperoleh yaitu laba-laba (ordo Araneae). Jenis laba-laba yang ditemukan yaiu laba-laba pemburu famili Oxyopidae. Livia-Tacza \& Sánchez, (2020) pada penelitiannya di lahan ubi jalar pada wilayah La Molina, Lima, Peru bahwa ordo Aranea memiliki kelimpahan dan keanekaragaman yang tinggi dengan 11 famili yaitu Gnaphosidae, Linyphiidae, Lycosidae, Mysmenidae, Oxyopidae, Salticidae, Scytodidae, Sicariidae, Theridiidae, Thomisidae and Trachelidae.

Tabel 2. Indeks keanekaragaman dan kelimpahan relatif hama dan musuh alami

\begin{tabular}{|c|c|c|c|c|c|c|c|c|c|c|c|}
\hline \multirow[b]{2}{*}{ No } & \multirow[t]{2}{*}{ Peran } & \multirow[b]{2}{*}{ Ordo } & \multicolumn{3}{|c|}{$\mathrm{A}$} & \multicolumn{3}{|c|}{ B } & \multicolumn{3}{|c|}{$\mathrm{C}$} \\
\hline & & & $\mathrm{H}^{\prime}$ & $\mathrm{E}$ & KR & $\mathrm{H}^{\prime}$ & $\mathrm{E}$ & KR & $\mathrm{H}^{\prime}$ & $\mathrm{E}$ & KR \\
\hline 1 & Hama & Coleoptera & 0,1060 & 0,0544 & 3,03 & 0,1270 & 0,0653 & 3,92 & 0,1300 & 0,0668 & 4,05 \\
\hline 2 & Hama & Orthoptera & 0,3585 & 0,1842 & 28,79 & 0,3599 & 0,1850 & 29,41 & 0,3632 & 0,1867 & 31,08 \\
\hline 3 & Hama & Hemiptera & 0,0635 & 0,0326 & 1,52 & 0,0771 & 0,0396 & 1,96 & 0,1300 & 0,0668 & 4,05 \\
\hline 4 & $\begin{array}{l}\text { Musuh } \\
\text { alami }\end{array}$ & Araneae & 0,2180 & 0,1120 & 9,09 & 0,3061 & 0,1573 & 17,65 & 0,2705 & 0,1390 & 13,51 \\
\hline 5 & Netral & $\begin{array}{l}\text { Hymenop- } \\
\text { tera }\end{array}$ & 0,3466 & 0,1781 & 50,00 & 0,3627 & 0,1864 & 43,14 & 0,3601 & 0,1851 & 44,59 \\
\hline 6 & Netral & Diptera & 0,1955 & 0,1005 & 7,58 & 0,1270 & 0,0653 & 3,92 & 0,0976 & 0,0502 & 2,70 \\
\hline
\end{tabular}

Keterangan: A = Ubi jalar kuning berdaun sempit, B = Ubi kuning berdaun lebar, dan C = Ubi jalar putih, $\mathrm{H}^{\prime}=$ Indeks keanekaragaman, $\mathrm{KR}=$ Kelimpahan relatif $(\%)$, dan $\mathrm{E}=$ Indeks kemerataan jenis.

Rendahnya keanekaragaman ini diduga disebabkan lahan ubi jalar ini sebelumnya telah digunakan untuk budidaya secara konvensional dengan penggunaan pupuk dan pestisida kimia sintetik. Lahan ubi jalar sebelumnya digunakan untuk tanaman cabai, terung, dan kacang panjang dengan penggunaan pestisida sintetik secara intensif. Walaupun saat penanaman ubi jalar hanya menggunakan pupuk organik, penggunaan bahan kimia sintetik pada pertanaman sebelumnya diduga dapat berpengaruh terhadap keberadaan populasi organisme pada pertanaman selanjutnya. Oleh karena itu, perlu penambahan biomassa hijauan atau bahan organik lain untuk perbaikan ekosistem tanah. Penelitian Sujak et al., (2018) pada tanaman tebu menjelaskan bahwa perbaikan kondisi ekosistem dapat dilakukan dengan penambahan biomassa secara terus menerus. Penambahan biomassa Clotalaria juncea dapat meningkatkan kelimpahan artropoda tanah, meningkatkan $\mathrm{C}$ organik tanah dari 0,62 menjadi 1,06 dan meningkatkan $\mathrm{N}$ dari 0,11 menjadi 0,03.

Indeks kemerataan jenis (E) dapat dilihat pada Tabel 2. menunjukkan sebaran kemerataan dengan ordo Hymenoptera yang mendominasi. Kelimpahan relatif (KR) dengan nilai tertinggi pada ketiga lahan ubi jalar kuning berdaun sempit, ubi jalar kuning berdaun lebar, dan ubi jalar putih (Tabel 2.) pada ordo Hymenoptera berturut-turut yaitu 50,00 \%; 43,14\%; dan 44,59\%. Putri et al., (2017) berdasarkan hasil penelitiannya bahwa jenis makrofauna dan mesofauna tanah epigeon yang mendominasi yaitu Hymenoptera (Formicidae) dan 
Colembolla (Isotomidae). Fauna tanah tersebut berperan dalam proses humifikasi dan mineralisasi atau pelepasan hara, bahkan ikut bertanggung jawab terhadap pemeliharaan struktur tanah. Tambunan et al., (2019) secara umum perbedaan keragaman serangga pada habitat satu dengan habitat lainnya dapat disebabkan karena terjadinya perbedaan tipe vegetasi tumbuhan dan kondisi faktor lingkungan abiotiknya.

Kelimpahan relatif (KR) pada ketiga lahan ubi jalar (Tabel 2.) menunjukkan nilai KR golongan hama ordo Orthoptera pada lahan ubi jalar kuning berdaun sempit, ubi jalar kuning berdaun lebar, dan ubi jalar putih berturut-turut 28,79\%; 29,41\%; dan 31,08\%. Sedangkan nilai KR golongan musuh alami ordo Araneae pada lahan ubi jalar kuning berdaun sempit, ubi jalar kuning berdaun lebar, dan ubi jalar putih berturut-turut 9,09\%; 17,65\%; dan 13,51\%. Nilai KR pada jenis hama menunjukkan seiring dengan nilai KR musuh alaminya. Adapun jenis serangga netral nilai KR tidak seiring dengan nilai KR hama. Qomariyah et al., (2018), informasi tentang kelimpahan musuh alami pada suatu lahan tanaman budidaya diperlukan untuk mengetahui kondisi stabilitas ekosistem pada suatu lahan. Pada penelitiannya bahwa salah satu jenis musuh alami hama pada tanaman budidaya yang seiring populasinya dengan jenis hama tertentu yaitu jenis predator.

\section{KESIMPULAN}

Indeks keanekaragaman hama ordo Coleoptera pada lahan ubi jalar kuning berdaun sempit, ubi jalar kuning berdaun lebar, dan ubi jalar putih berturut-turut 0,1060; 0,1270; dan 0,1300. Indeks keanekaragaman hama ordo Orthoptera pada lahan ubi jalar kuning berdaun sempit, ubi jalar kuning berdaun lebar, dan ubi jalar putih berturut-turut 0,3585; 0,3599; dan 0,3632. Indeks keanekaragaman hama ordo Hemiptera pada lahan ubi jalar kuning berdaun sempit, ubi jalar kuning berdaun lebar, dan ubi jalar putih berturut-turut 0,0635; 0,0771; dan 0,1300. Indeks keanekaragaman musuh alami ordo Araneae pada lahan ubi jalar kuning berdaun sempit, ubi jalar kuning berdaun lebar, dan ubi jalar putih berturut-turut 0,2180; 0,3061; dan 0,2705. Ketiga lahan ubi jalar memiliki indeks keanekaragaman yang rendah.

\section{DAFTAR PUSTAKA}

Afriani, R., \& Suati, S. (2021). Keragaman Serangga Permukaan Tanah Pada Ekosistem Sawah Di Dusun Sawahan Desa Pagal Baru Kecamatan Tempunak Kabupaten Sintang. Edumedia : Jurnal Keguruan Dan Ilmu Pendidikan, 5(1), 23-26.

Basna, M., Koneri, R., \& Papu, A. (2017). Distribusi Dan Diversitas Serangga Tanah Di Taman Hutan Raya Gunung Tumpa Sulawesi Utara. Jurnal MIPA Unsrat Online, 6(1), 36-42.

BPS Kabupaten Banjarnegara. (2014). Kecamatan Madukara dalam Angka. BPS Kabupaten Banjarnegara. http://banjarnegarakab.bps.go.id/?hal\%0A= publikasi_detil\&id=945.

Guru, P. N., Shrilakshmi, R. G., \& Patil, R. K. (2016). Effect of Mulch On Soil Insects And Other Arthropods. Progressive Research - An International Journal, 11(Special-I), 280-282.

Livia-Tacza, C., \& Sánchez, G. (2020). Soil arthropods associated with sweetpotato crop (Ipomoea batata L.) in La Molina, Lima, Peru. Peruvian Journal of Agronomy, 4(1), 1-9.

Magurran, A. E. (2004). Measuring Biological Diversity. Blackwell Science Ltd. https://www2.ib.unicamp.br/profs/thomas/N\%0AE002_2011/maio10/Magurran\%25202004\%252\%0A0c 2-4.pdf.

Oktafitria, D., Hidayati, D., \& Purnomo, E. (2019). Diversitas Serangga Tanah Di Berbagai Tipe Tanah Pada Lahan Reklamasi Bekas Tambang Kapur Kabupaten Tuban. Florea, 6(1), 28-35.

Pinontoan, O. R., Lengkong, M., \& Makal, H. V. G. (2011). Hama Penting Tanaman Ubi Jalar (Ipomea batatas L.(Lamb)) Di Kabupaten Minahasa, Minahasa Utara, Dan Kota Tomohon. Eugenia, 17(2), 114-122.

Putri, D. F. A., Kusuma, Z., \& Arisoesilaningsih, E. (2017). Kajian Diversitas Makrofauna Dan Mesofauna Tanah Pada Sawah Padi Semiorganik Dan Konvensional Di Kabupaten Malang, Jawa Timur Indonesia. Jurnal Kesehatan Dan Sains, 1(1), 1-8.

Qomariyah, N., Hayati, A., \& Zayadi, H. (2018). Diversitas Serangga Predator yang Datang pada Lahan Tanaman Cabai Rawit (Capsicum frutescens L) Berdasarkan Variasi Temporal di Desa Bumianyar Kecamatan Tanjungbumi Kabupaten Bangkalan. E-Jurnal Ilmiah Biosainstropis (Bioscience-Tropic), 4(1), 22-30.

Restu, I. W. (2002). Kajian Pengembangan Wisata Mangrove di Taman Hutan Raya Ngurah Rai Wilayah Pesisir Selatan Bali. Institut Pertanian Bogor.

Saleh, N., Indiati, S. W., Widodo, Y., Sumartini, \& Rahayuningsih, S. A. (2015). Hama, Penyakit, dan Gulma 
pada Tanaman Ubi Jalar Identifikasi dan Pengendaliannya. Pusat Penelitian dan Pengembangan Tanaman Pangan Badan Penelitian dan Pengembangan Pertanian.

Setiawan, H. A., Asep Setiawan, \& Rahayu, M. S. (2019). Teknik Perbanyakan Cepat Bibit Ubi Jalar (Ipomoea batatas L. Lam) dengan Perlakuan Rootone F dan Pupuk Daun. Bul. Agrohorti, 7(3), 271-280.

Siregar, A. S., Bakti, D., \& Zahara, F. (2014). Keanekaragaman Jenis Serangga Di Berbagai Tipe Lahan Sawah. Jurnal Online Agroekoteknologi, 2(4), 1640-1647.

Sujak, Sunarto, D. A., \& Subiyakto. (2018). Pengaruh Penambahan Biomassa di Lahan Kering terhadap Diversitas Arthropoda Tanah dan Produktivitas Tebu. Buletin Tanaman Tembakau, Serat \& Minyak Industri, 10(1), 21-31.

Tambunan, J., Ginantra, I. K., \& Watiniasih, N. L. (2019). Diversitas Serangga Hutan Tanah Gambut Di Palangkaraya Kalimantan Tengah. Metamorfosa:Journal of Biological Sciences, 6(2), 156-164.

Warohmah, M., Karyanto, A., \& Rugayah, R. (2018). Pengaruh Pemberian Dua Jenis Zat Pengatur Tumbuh Alami Terhadap Pertumbuhan Seedling Manggis (Garcinia mangostana L.). Jurnal Agrotek Tropika, 6(1), 15-20. 